\title{
FLIPPING OUT - REFLECTIONS ON TEN YEARS OF DEVELOPMENT, INNOVATION AND DESIGN IN TECHNOLOGY-RICH COLLABORATIVE LEARNING SPACES AND ACTIVE LEARNING PEDAGOGICAL CAPACITY BUILDING
}

\author{
Chris Whittaker and Elizabeth S. Charles \\ Dawson College \\ cwhittaker@dawsoncollege.qc.ca, echarles@dawsoncollege.qc.ca
}

\begin{abstract}
Drawing broadly on the reflective practices of design case research, this paper reviews ten years of development, innovation and design in technology-rich collaborative learning classrooms and active learning pedagogy at Dawson College. Grounded in a process of Design-Based Implementation Research and leveraging Researcher-Practitioner Partnerships, Dawson College has been a leading hub of evidence-based pedagogical development in Quebec for a decade. By recognizing the important interplay of technology, spaces, tools, pedagogy and design, our institution has sustained continual growth in capacity and infrastructure when it comes to studentcentred learning, and it has learned important lessons in capacity building that can be applied to higher-education institutions broadly and to engineering in particular.
\end{abstract}

Keywords: Active Learning Classroom design, Technology-rich learning environments, evidence-based pedagogical practices.

\section{INTRODUCTION}

It is not an exaggeration to say that institutions of higher education around the world are undergoing a dramatic transformation when it comes to the design, use and support of learning spaces [1]. Driven by the ubiquitous nature of information in a modern world, enabled by digital technologies, and accelerated by an ever developing understanding of how people learn, traditional classroom spaces that were centered on the transmission of information are rapidly being reconceived and transformed by designs that are centered on the learner and on the process of constructing knowledge - what can broadly be called Active Learning Classrooms (ALCs) [2]. However, change is hard, and developing new learning environments while building the pedagogical capacity necessary to make them successful and sustainable is a significant challenge that requires new approaches to traditional models of faculty development [23].
Active Learning is an umbrella term for studentcentered pedagogical practices that engage students cognitively, affectively and socially [18][19] and that get students "doing things and thinking about the things they are doing" [4]. Compared to traditional, instructor-centered models of instruction that focus on the transmission of information and expertise from the teacher to student, Active Learning focuses on engaging students in a broad range of meaningful learning activities - including elements of traditional pedagogies such as mini-lectures that leverage tools and interactions with others [24].

The theoretical foundations for Active Learning and the work considered here are rooted in the social constructivist perspective of Vygotsky [25] in which learning is seen as a dynamic process of co-construction [20]. Our interpretation of social constructivism is heavily influenced by situated cognition [17], distributed cognition [9], and regulated learning [14] in that learning dynamically leverages the affordances of an environment that includes individuals, artifacts, tools, relationships, as well as processes of self-regulation, co-regulation and shared regulation. Importantly, technology and design play a central role in supporting collaboration, the creation of learning artifacts and in the orchestration of learning activities in the technology-rich learning spaces considered here [10].

The evidence that Active Learning approaches are beneficial compared to traditional teacher-centered instruction dates back several decades and includes evidence from engineering specifically [21]. Within STEM fields more broadly, Active Learning has been shown to increase conceptual learning, improve exam scores, reduce failure rates, increase attendance, improve attitudes towards learning, and develop skills that employers are looking for in the $21^{\text {st }}$ century. The most complete and convincing accounting of the benefits of Active Learning in STEM fields comes from Freeman et al.'s 2014 metaanalysis of 225 studies [12].

The evidence that Active Learning Classrooms (ALCs) can further improve teaching and learning when coupled 
with active learning pedagogies is also growing steadily. It's not so much that ALCs allow instructors and learners to do different things, it's that they can do the kinds of things that are central to active leaning more effectively, flexibly, deeply and efficiently. Active Learning Classrooms - also called next-generation learning spaces [5] and future learning spaces [13] - are learning spaces that are purposefully designed for enacting active learning strategies, and their numbers are steadily growing in higher education institutions. The variety of designs and the complexity of the interactions between design, technology, pedagogy, and the activities that go on in these spaces makes this research challenging. However, there is clear evidence that designed learning spaces can contribute to better student performance, allow students to exceed their learning expectations, facilitate the orchestration of complex teaching scripts, shape teaching and learning expectations and more [1].

To add to this emerging body of research, this paper reviews ten years of development, innovation and design of technology-rich collaborative learning classrooms and active learning pedagogy at Dawson College. To do so, it uses a mixed-methods approach to examine the process and extract lessons that may be applied specifically toward
Engineering education. Using a review of systematic personal notes by the first author, documents and reports created during the development process, administrative data, various presentations at conferences, and reflections with colleagues from STEM and the Learning Science fields who contributed to the design and development processes, this paper draws from the research field of Design Cases [3][22] to disseminate the episodic memory acquired by our community of researchers and practitioners. Using the results from a series of research papers, published by our research team on the functionality and use of the Dawson ALCs, this paper further draws on qualitative and quantitative methods to provide a systemic and holistic review so that others may build upon the principles gleaned from our successful experiences.

\section{MAIN BODY}

\subsection{Who We Are}

Dawson College, located in Montreal, is the largest of Quebec's publicly funded post-secondary CEGEP institutions. It provides two-year pre-university programs and three-year professional programs to more than 10,000 students, employs over 600 faculty and has just over 100

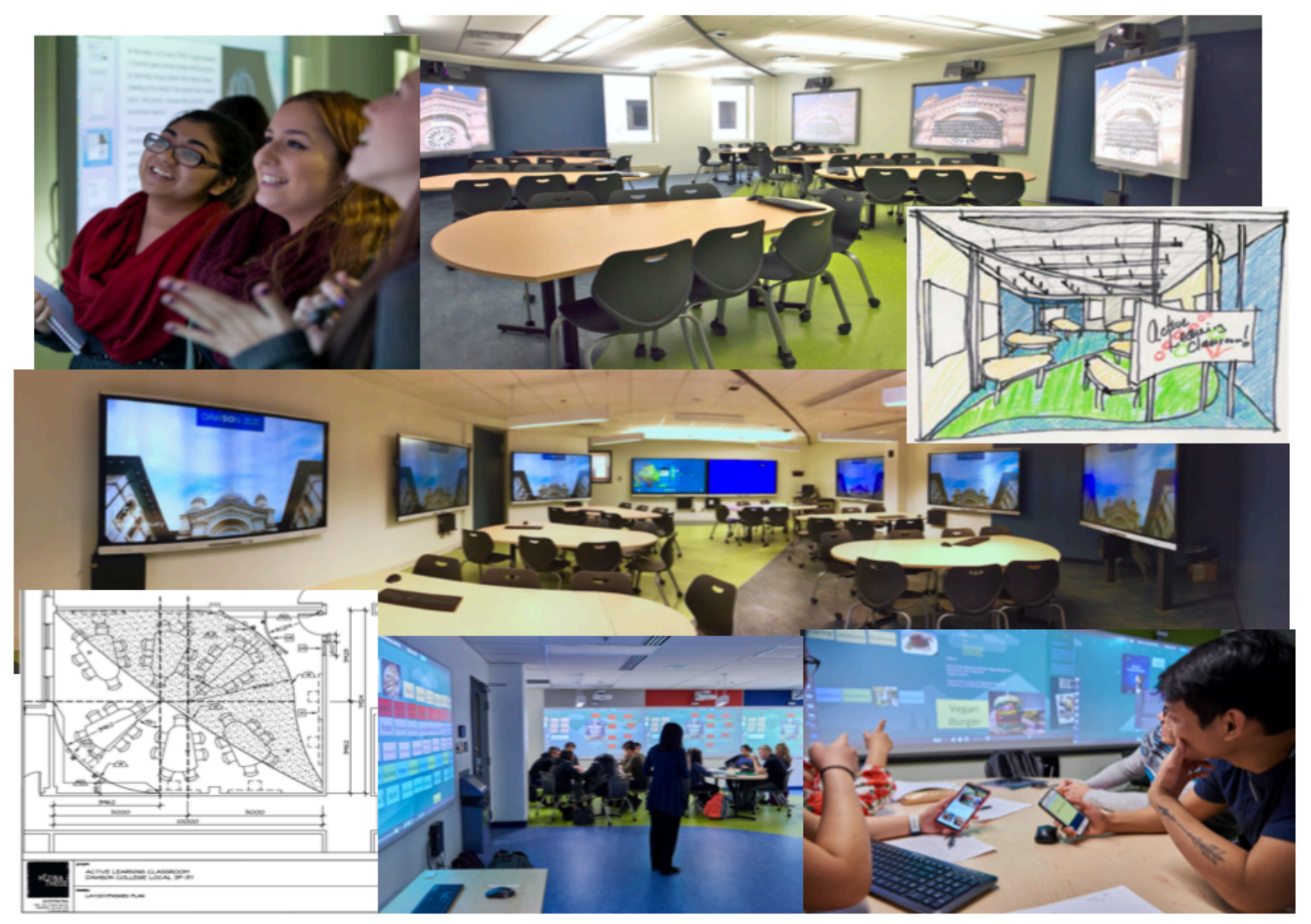

Figure 1. Pictures and layout drawings of technology-rich AL Classrooms (ALCs) at Dawson College. (Sketch and layout drawings by Vezina Thode Architects Inc.) 
classroom spaces. Importantly, classes in cegep are small (typically 30 to 45 students) and the instructors are content experts having completed graduate degrees in their field and are not necessarily pedagogical experts.

Since 2009, the authors have been driving a process of change that has included the design and construction of twelve Active Learning classrooms and the development of the pedagogical capacity to use them effectively. What started as a redesign process for one department's teaching labs, has grown into a broad and diverse movement across the college to develop classrooms for Active Learning regardless of discipline. Leaning heavily on an iterative process of design, research and implementation - what Fishman et al. call Design-Based-Implementation Research (DBIR) [11] - and leveraging long-term collaborations where educators and researchers work together to study and solve pressing problems of practice what are broadly called Researcher-Practitioner Partnerships (RPPs) [8] - we have put evidence and sustainability at the heart of our classroom development process.

The authors of this paper have been teaching at Dawson for over two decades and as part of the reflective practices of design case research [3][22] it is appropriate to highlight our background and acknowledge our role in the process being reflected upon here. Chris Whittaker holds a B.Sc. and M.Sc. in Engineering Physics and is currently completing a Ph.D. in The Department of Didactics in the Faculty of Education at the Université de Montréal. He has received institutional, regional and national-level awards for teaching and innovation. Elizabeth Charles is a Learning Scientist who completed her $\mathrm{PhD}$ in Educational Technology at Concordia University and did a post-doc at the Georgia Institute of Technology, in Atlanta, studying project-based science education for middle-school students. For the past 15 years, she has been the primary investigator on a number of successive multi-year research projects focused on college-level science education. In the last half-decade, she has also developed mechanisms to support the development of researcher-practitioner partnerships and a multi-institutional project that builds pedagogical capacity through the development of resources, tools and an annual conference (www.saltise.ca).

\subsection{Beginnings}

In order to start us along our path - that is, to begin tracing our episodic memory of development - we begin by considering one of our early research efforts, one that helped focus the development of our classroom designs and that reinforced a key finding in the Learning Sciences literature: that conversations between students matter. In 2009, we published a paper with colleague Nathaniel Lasry that sought to better understand the mechanism behind the success of a particularly impactful teaching strategy called Peer Instruction [16]. Peer Instruction (PI) dramatically increases conceptual understanding in STEM fields by engaging students in an interactive process of reflecting, voting, discussing with peers, and then re-voting on conceptual multiple-choice questions [15]. Our study sought to illustrate what was responsible for PI's learning gains: was it the extra time between votes, was it the internal cognitive reflections, or was it the conversations between students? In our quasi-experimental study, we asked an identical sequence of conceptual questions to three groups of students. In one case, our intervention consisted of distracting the students with meaningless chitchat between votes. In the second intervention, we gave the students quiet time to reflect between polling but did not let them interact with peers. Finally, in the third condition, we asked students to discuss with peers between votes. In each of the conditions the time between votes was identical. The results, shown below in Figure 2, clearly show that student learning gains were strongest when they engaged in conversations with peers - and this, in part, helped to focus our classroom efforts on designing spaces that facilitate peer interactions and conversations.

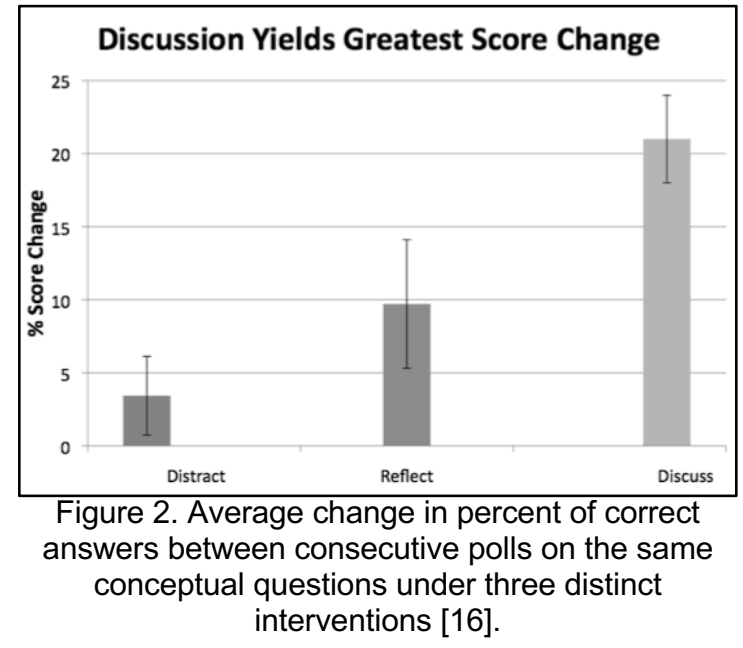

As we were conducting the PI study described above, interest in the growing bank of evidence for AL pedagogical approaches in the Physics Education Research (PER) literature led to a number of colleagues from the physics department becoming interested in re-thinking our teaching lab spaces. Through a combination of events that included a timely opportunity for infrastructure renovation funds, the lead author of this paper led an effort to redesign the Dawson Physics Department's teaching labs. After a review of needs, a visit to several innovative lab spaces including the SCALE-UP and TEAL classrooms at North Carolina State University and M.I.T. as well as the Dickinson College physics labs - an iterative process of design was undertaken that involved: 1) a small working committee; 2) a broader committee of physics faculty and lab technicians, college administrators, and representatives from audio-visual, information technologies and physical plant services, as well as; 3) numerous consultations with 
the entire physics department. Importantly, this broad and sometimes laborious process was deemed to have been crucial in the success of the renovation project, and once completed, these new labs then served as the focus for further research. Surprisingly, these new labs also began to draw attention from other areas of the college, and it was a combination of the research lessons from these spaces and growing interest from outside of physics that led to a push for the development of a general-purpose AL classroom.

In the physics department's redesigned Active Learning teaching labs, students no longer sat in traditional frontfacing rows but around hexagonal-shaped "pods" where up to four could engage in conversations and collaboratively work together (see Figure 3). From video and in-person observations the importance of learning artifacts - like student notes and work/problem sheets - in such a classroom emerged. Not only were the conversation students had important, but artifacts that generated and focussed those conversations were important as well. Significantly, two issues about artifacts and each students' access to them also arose: First, the orientation of artifacts became an issue because individual artifacts such as the drawings on a piece of paper were upside-down for those sitting along the opposite sides of the table, and; Second, the proximity of students was of great importance when they wanted to exchange artifacts or show them to each other.

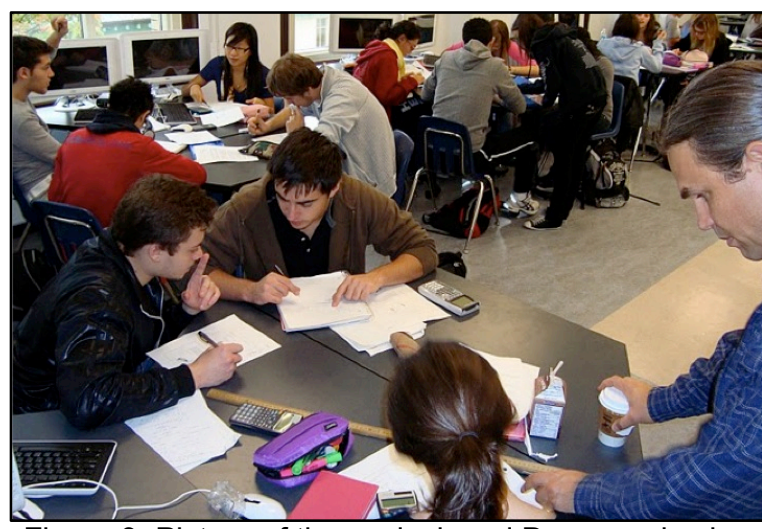

Figure 3. Picture of the re-designed Dawson physics lab showing the students sitting around hexagonal tables and focused on paper artifacts.

Another important design lesson that emerged from observations in our redesigned physics labs - indeed one that would become a focal point for all subsequent ALC designs - centred on the use of Interactive White Boards (IWBs) in the classroom. In a memorable clip of video data, students can be seen approaching the instructor's IWB after he had finished a mini-lecture and was circulating around the room to coach groups. Going behind his back, the students scrolled back through the teacher's notes and they engaged in a dialog in which they can be seen gesturing and discussing (see Figure 4). It was in this context that we began to see the IWB not simply as a teaching tool, but as a learning tool that belonged in the hands of the students.
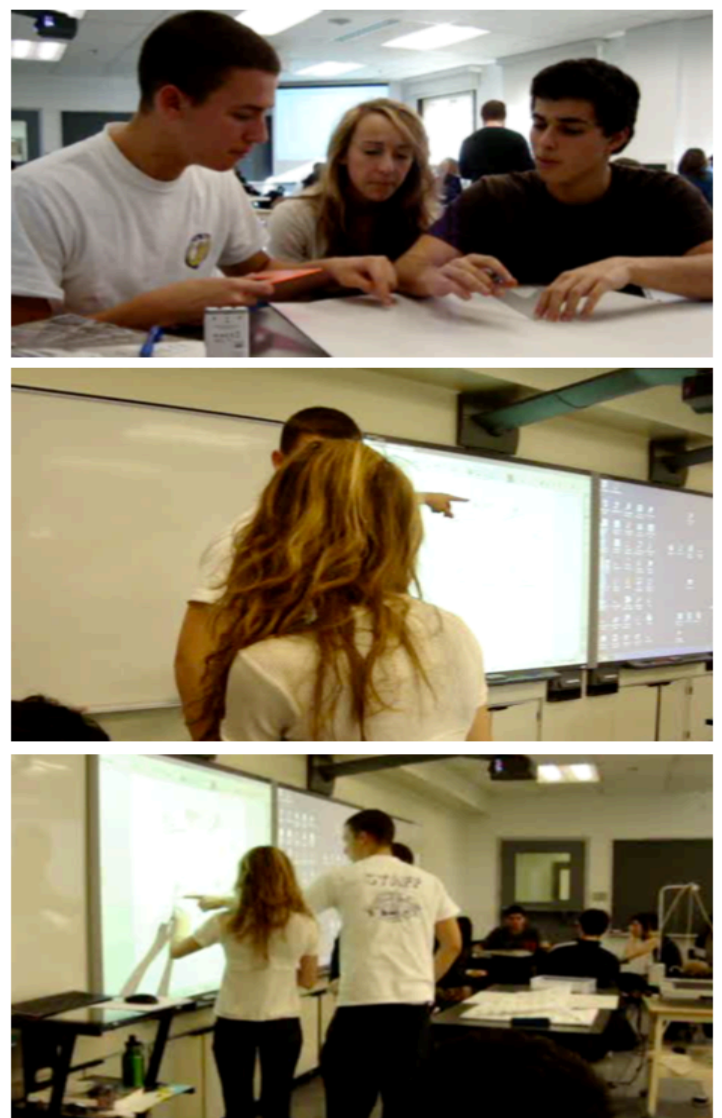

Figure 4. Still photos taken from video data showing students pointing to, approaching and interacting with an artifact on a teacher's IWB.

At the same time as we were learning about the physical design of the classroom and affordances provided by the technologies within it, a second aspect of our research efforts focussed our attention on the most important aspect of any classroom: the pedagogical expertise exercised within it. In a study that compared two pedagogical approaches in two types of classroom settings through a quasiexperimental $2 \times 2$ factorial design we were able to demonstrate that student conceptual gains, as measured by a standardized and widely used instrument called the Force Concept Inventory (FCI), were higher when an Active Learning (AL) pedagogical approach was used, and were highest when AL pedagogy matched AL classroom design. Figure 5 shows these results in each of the four experimental conditions and it is clear that AL pedagogies in both traditional and AL designed classrooms resulted in higher learning gains than when the pedagogical paradigm was traditional. Interestingly however, student scores in the classroom designed for active learning were lower when traditional pedagogies were employed than all other conditions. From this, we concluded that "redesigned sociotechnological environments will not be effective 


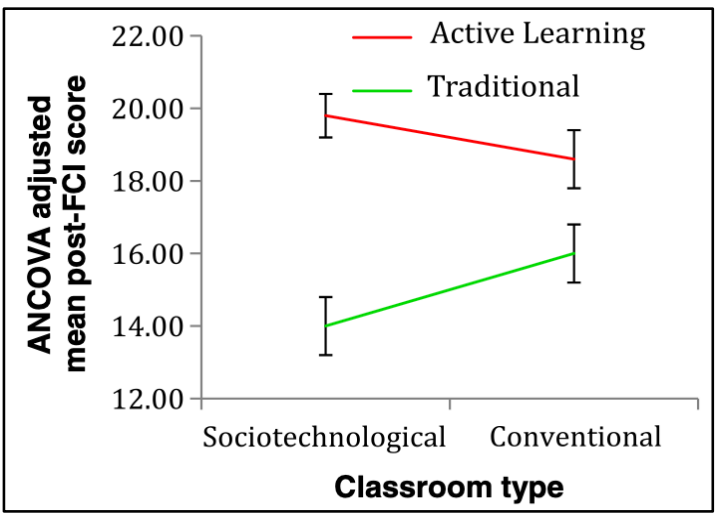

Figure 5. Independent of classroom type, students in active learning pedagogies have significantly greater mean post-FCl score, when adjusted for pre-FCl score. However, when a traditional pedagogy is used in an Active Learning Classroom (ALC) conceptual gains are lowest [23]. These results caution against seeing ALCs as a magic pill. In order for them to work, form (design) must meet function (pedagogy).

unless resources are also directed towards helping instructors understand why and how to use studentcentered pedagogies, thereby promoting a shift in their epistemic frameworks." [15].

\subsection{The First Dawson Active Learning Classroom}

As interest in the redesigned physics labs grew more broadly within the college and as the lessons learned from them were articulated, interest in designing, developing and constructing a general-purpose ALC grew as well. In a process similar to that used for the physics labs the development of this new space was driven by the current authors, included administrators, technicians and professionals as well as researchers, but this time it featured faculty from across the college. The most important of the design principles that emerged in this process was to centre the room design on IWBs mounted around the perimeter of the room for groups of students to use as interactive spaces for the creation/manipulation of learning artifacts. Specific instantiations of the initial designs continued building on the idea used in the physics labs of small modular tables that could be arranged in a multitude of ways however that was eventually abandoned for two reasons. First, with a fixed arrangement of IWBs along the walls, it was recognized that the smallest grain size for groups was limited by the number of IWBs. Second, our live-in experience of the physics labs with smaller, modular tables that can rearranged resulted in an awareness that: the stability of smaller tables can be problematic; rearranging tables takes time and creates noise; frustrations arise when teachers arrive for class and the room arrangement is not as expected; tables and the floor are easily damaged in the process of re-arranging, and; the seams between modular tables when arranged together can be problematic in that it becomes more difficult to move artifacts - such as books and papers around when surfaces are uneven or when papers can slip through the gaps. With these in mind, and in order to get a better idea of what designs might work best, it was decided to do a mock-up of a selected space. It was from this mockup process that a unique and innovative table design emerged that would become the foundation for most of our future efforts.

2.3.1 An innovative table design emerges. Equipped with small tables, 4'x8' cardboard sheets, Exacto knives and tape, a handful of interested teachers and professionals gathered in an emptied classroom to try various designs out. We started with the same circular table designs that are typical of the popular SCALE-UP classroom designs [2], however, in considering these kinds of tables two principal problems were identified: First, a bottle-neck effect was created between tables that restricted the movement from the inner centre of the room to the outer perimeter and thus created accessibility issues for the IWBs that were to be mounted on the walls, and; second, large circular tables mean that students sitting opposite each other are distant and the centre forms a "dead" space of sorts. The solution to both problems emerged in a moment of collective creativity in which the first author of the present paper cut the sides off a circular mock-up tabletop and created "truncated-egg" shaped tables that solved both the bottleneck and dead-space problems but provided an opportunity to enhance group attention and focus on the wall-mounted IWBs. See Figure 6.

2.3.2 Beware: "Coloured lights can hypnotize..." As the design process was drawing to a close for this firstgeneration AL classroom, the college hired an architect to refine our designs. As expected, the architect extended our work by introducing a theme and colour scheme that were intellectually and visually very pleasing. However, in a rush to finalize the designs, we were distracted by the attractive package of drawings and didn't notice that the architect had changed our design in a subtle, yet pedagogically important way. Shortly after seeing the architect's work and after approving of the design we realized the change - which consisted of moving the "front" of the room from the long side (where the side of the classroom would traditionally be) to the short-end of the room (where the "front" traditionally is). The purpose of our design - with the "front" along the long wall (as shown in Figure 6) - was to reduce the depth so that no student was sitting more than two or three students away from the instructor or the artifact creation spaces - the IWBs. With the change made by the architect, there were now not only students behind students, but tables behind tables. In hindsight, we regretted missing the change. We had been dazzled by the pretty pictures, or as the classic Canadian song by The Guess Who warns, "coloured lights can hypnotize, sparkle someone else's eyes". 


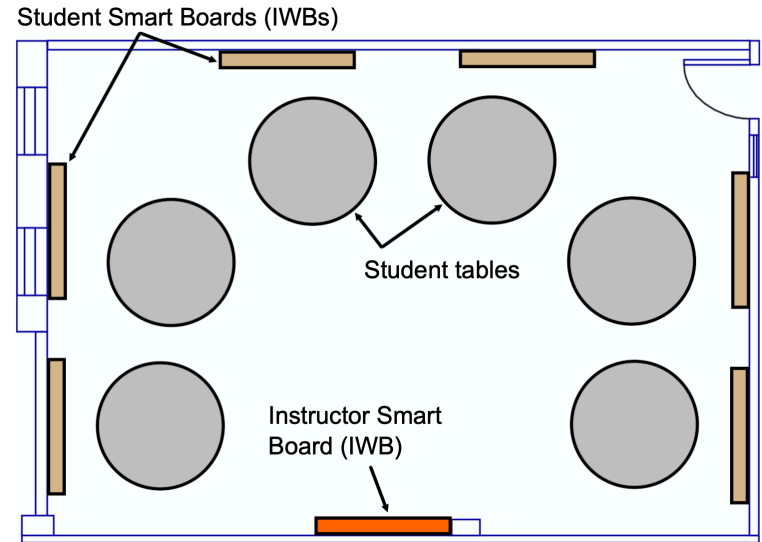

Figure 6a. Initial AL classroom setup with SCALE-UPlike round tables.

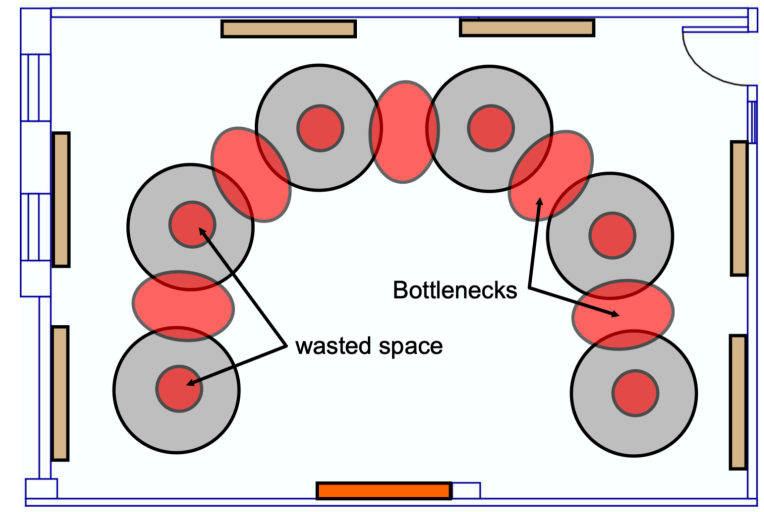

Figure 6b. Problem areas - bottlenecks and wasted spaces - with initial setup

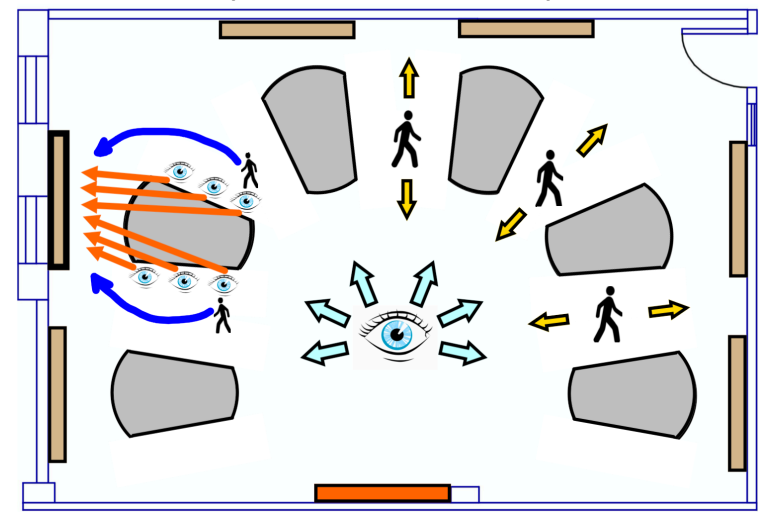

Figure 6c. Innovative table design to eliminate problem areas with round tables. Our design allows for easy visual and physical access around the room.

2.3.3 The emergence of a Learning Community as a vehicle for pedagogical change. Importantly, once the first classroom was built, considerable effort was needed to learn how to use it as an effective pedagogical tool. We started to organize meetings that brought together the teachers who were using the room, researchers and pedagogical experts who had AL expertise, along with support professionals (especially IT folks) to learn from each other and share our successes/failures. Over time, the initial (and relatively informal) community grew and developed into a formal Faculty Learning Community (FLC) that has since evolved into a hybrid of an FLC and a Community of Practice (CoP). We distinguish between an FLC and a CoP by the transformative nature of the efforts they undertake. In an FLC the goal is to learn a new practice whereas a $\mathrm{CoP}$ is less about learning a new practice than it is about refining and improving an already existing practice.

\subsection{Subsequent Iterations of AL Classrooms and the Lessons Learned.}

As the Learning Community around the first Active Learning Classroom (ALC) grew, we began a methodical process of growing and diversifying our classrooms as capacity and demand grew. From a single general-purpose ALC in 2011, to 10 today - see Figure 1 - we have come to categorize those that feature student-dedicated IWBs as "high-tech" rooms and those that feature student-dedicated whiteboards as "low-tech". Importantly, we continued to approach development from an iterative, evidence-based process that, in retrospect, can be accurately described as a Design-Based Implementation Research (DBIR) process [11]. And while the details of each iteration will not be explored here, some of the end products, patterns, and lessons are worth highlighting now.

2.4.1 Control of Scheduling. Data presented earlier in this paper (see Fig. 5) suggests that a traditional pedagogical approach in an Active Learning space leads to lower learning gains than traditional approaches in traditional spaces. It is therefore important that institutions take steps to make sure that the scheduling of AL classrooms is driven by matching pedagogy with space. In our case, the authors - as leaders of the community of designers, users and supporters of the space - were granted control over the task of assigning teachers to AL classrooms. Working with the guidance of the community, we select teachers based on criteria that recognize the investment made in adapting their pedagogical practices and activities, welcoming newcomers who embrace Active Learning, and give priority to those who contribute to the development of the community and their pedagogy.

2.4.2 Investing in Pedagogical Capacity Building Early and Often. In reflecting on our experience, we believe that an essential element of the sustained growth of our classrooms (see Figure 7: orange dots/line) has been the parallel development of a community of practitioners who learn how to use them as effective and efficient pedagogical tools. Guided by an extensive literature on the benefits of Learning Communities, we decided to invest significantly - including an initial investment that was disproportionate to the number of ALCs (see Figure 7: blue columns) - by releasing teachers from a part of their teaching load to develop and share their own pedagogical expertise, and then to develop resources for 
Active Learning that could be used by the broader Dawson Active Learning Community (DALC). Elsewhere we have presented on the benefits of our Learning Community as an agent for change in pedagogical capacity, including the benefits of using active learning classroom environments as focal points for joint work and boundary crossings [26].

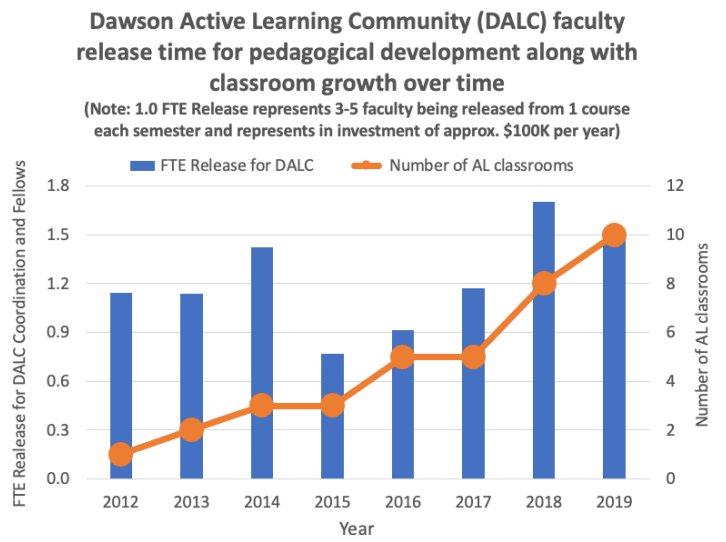

Figure 7. Despite only a handful of ALCs in the early years, we invested significantly - and disproportionally relative to the number of classrooms - in releasing teachers for the development of the pedagogical capacity to use them. This initial investment, along with investments in subsequent years is seen as important in the sustained and effective development of Dawson's ALCs.

2.4.3 IWBs as Powerful Learning Tools in Engineering. Our use of Interactive White Boards (IWBs) has evolved and their use as tools are particularly well suited to teaching and learning in STEM. At the very heart of Active Learning is the notion that students need to construct knowledge through a process that is socially mediated and that leverages tools and resources in an authentic environment. Likewise, at the heart of engineering education is the need to have students "do" rather than simply listen. By providing students with a shared, publicly displayed, and dynamic space - such as an IWB - we have found that students can create, manipulate and have meaningful conversations around artifacts, representations and processes that make learning tangible. Importantly, physical and visual access to these spaces as well as carefully designed activities - especially ones that encourage the collaboration and engagement of all students - are critical to their successful uptake and use [6].

2.4.4 A hierarchy of student engagement. When it comes to the level of engagement by groups of students, video data analysis has revealed three distinct phases in the way our technology-rich ALCs are used and in which it is possible to identify an increasing order of student engagement: 1) Executive mode in which one student manipulates the IWB artifact while other students sit back and watch or direct; 2) Tutor/Tutee mode in which students interact in a dynamic and participatory form that is similar to a tutor helping a tutee, and 3) Full Collaborative mode in which peers stand at the IWB to jointly construct and manipulate a learning artifact and engage in a truly collaborative process (this process requires IWBs with multi-touch capabilities). Through carefully designed activities and purposeful orchestration, our teachers have learned how to push students out of mode 1 and into modes 2 and 3 on a consistent basis. Students engaged in these modes are pictured in Figure 8.

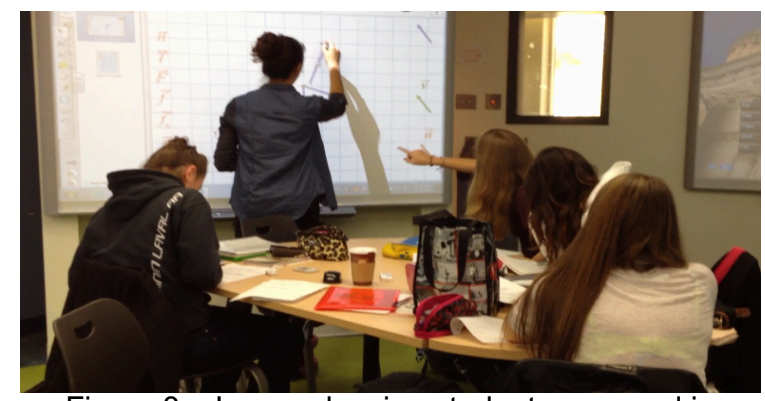

Figure 8a. Image showing students engaged in Tutor/Tutee mode at an IWB.

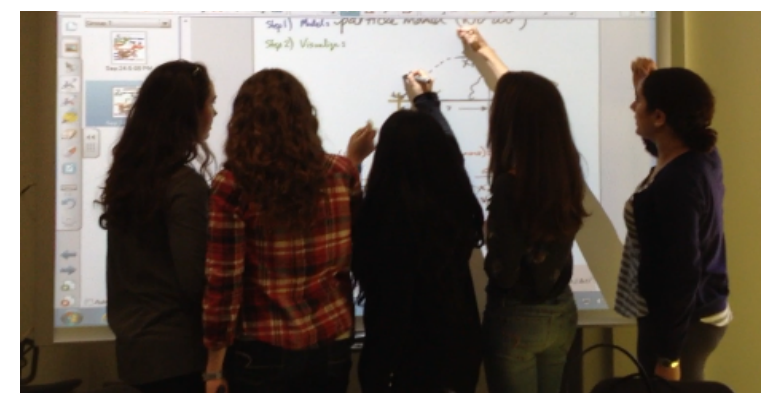

Figure 8b. Image showing students engaged in Full Collaborative mode at a multi-touch IWB.

\section{CONCLUSIONS}

This review of our decade-long efforts to design and sustain Active Learning Classrooms (ALCs) as well as the pedagogical and institutional capacity to use them effectively has been presented here. Reflecting on the use of an iterative, Design Based Implementation Research model, this paper has built on our previous research efforts around peer-interactions, the use of learning artifacts, and the importance of design and accessibility to illustrate several iterations in ALC development at Dawson College. Drawing more specifically on our experiences to develop and sustain pedagogical capacity, we have also attempted to highlight the importance of investing in such efforts and provided insights into what has worked effectively for us. The specific lessons from our efforts that were highlighted in this paper include: the general importance of an evidence-based and iterative design, implementation and assessment process in sustainable and meaningful space development; the importance of institutional systems to 
support resource development; the importance of early and repeated investment in supporting Faculty Learning Communities; the important revelation that Interactive White Boards (IWBs) are powerful learning tools and as such should be put in the hands of students; and finally, the importance of recognizing modes of collaborative student behaviour and creating the pedagogical know-how to orchestrate richer opportunities for engagement in learning within these Active Learning Classrooms.

\section{References}

[1] Baepler, Paul, J. D. Walker, D. Christopher Brooks, Kem Saichaie, and Christina I. Petersen, A guide to teaching in the active learning classroom: History, research, and practice. Sterling, Virginia: Stylus Publishing, LLC, 2016. 269pp. \{ISBN: 978-1-62036-300-3\}

[2] Beichner, Robert J. "History and evolution of active learning spaces." New Directions for Teaching and Learning 2014.137 (2014): 9-16.

[3] Boling, Elizabeth. "The need for design cases: Disseminating design knowledge." International Journal of Designs for Learning 1, no. 1 (2010).

[4] Bonwell, Charles C., and James A. Eison. Active Learning: Creating Excitement in the Classroom. 1991 ASHE-ERIC Higher Education Reports. ERIC Clearinghouse on Higher Education, The George Washington University, One Dupont Circle, Suite 630, Washington, DC, 1991.

[5] Byers, Terry, Wesley Imms, and Elizabeth Hartnell-Young. "Making the case for space: The effect of learning spaces on teaching and learning." Curriculum and Teaching 29, no. 1 (2014): 5-19.

[6] Charles, Elizabeth S., Nathaniel Lasry, Kevin Lenton, Chris Whittaker, and Michael Dugdale. "Écosystème pédagogique et artéfacts épistémiques: des environnements d'apprentissage qui favorisent l'engagement étudiant." (2017).

[7] Charles, Elizabeth, Jim Slotta, Robert Cassidy, Michael Dugdale, Chao Zhang, and Kevin Lenton. "How Teachers Implement Active Learning" (2019).

[8] Coburn, C.E. and Penuel, W.R., 2016. Research-practice partnerships in education: Outcomes, dynamics, and open questions. Educational Researcher, 45(1), 48-54.

[9] Cole, Michael, and Yrjö Engeström. "A cultural-historical approach to distributed cognition." Distributed cognitions: Psychological and educational considerations (1993): 1-46.

[10] Dillenbourg, Pierre, and Patrick Jermann. "Technology for classroom orchestration." In New science of learning, pp. 525-552. Springer, New York, NY, 2010.

[11] Fishman, Barry J., William R. Penuel, Anna-Ruth Allen, Britte Haugan Cheng, and N. O. R. A. Sabelli. "Designbased implementation research: An emerging model for transforming the relationship of research and practice." National society for the study of education 112, no. 2 (2013): 136-156.

[12] Freeman, Scott, Sarah L. Eddy, Miles McDonough, Michelle K. Smith, Nnadozie Okoroafor, Hannah Jordt, and Mary Pat Wenderoth. "Active learning increases student performance in science, engineering, and mathematics." Proceedings of the National Academy of Sciences 111, no. 23 (2014): 8410-8415.

[13] Hod, Yotam. "Future learning spaces in schools: Concepts and designs from the learning sciences." Journal of Formative Design in Learning 1, no. 2 (2017): 99-109.

[14] Järvelä, Sanna, and Allyson F. Hadwin. "New frontiers: Regulating learning in CSCL." Educational Psychologist 48, no. 1 (2013): 25-39.

[15] Lasry, Nathaniel, Elizabeth Charles, and Chris Whittaker. "When teacher-centered instructors are assigned to studentcentered classrooms." Physical Review Special TopicsPhysics Education Research 10, no. 1 (2014): 010116.

[16] Lasry, Nathaniel, Elizabeth Charles, Chris Whittaker, and Michael Lautman. "When talking is better than staying quiet." In AIP Conference Proceedings, vol. 1179, no. 1, pp. 181-184. American Institute of Physics, 2009.

[17] Lave, Jean, and Etienne Wenger. Situated learning: Legitimate peripheral participation. Cambridge university press, 1991.

[18] Linton, Debra L., Wiline M. Pangle, Kevin H. Wyatt, Karli N. Powell, and Rachel E. Sherwood. "Identifying key features of effective active learning: the effects of writing and peer discussion." CBE-Life Sciences Education 13, no. 3 (2014): 469-477.

[19] Meltzer, David E., and Ronald K. Thornton. "Resource letter ALIP-1: active-learning instruction in physics." American journal of physics 80, no. 6 (2012): 478-496.

[20] Palincsar, A. Sullivan. "Social constructivist perspectives on teaching and learning." Annual review of psychology 49, no. 1 (1998): 345-375.

[21] Prince, Michael. "Does active learning work? A review of the research." Journal of engineering education 93, no. 3 (2004): 223-231.

[22] Smith, Kennon. "Producing the rigorous design case." International Journal of Designs for Learning 1, no. 1 (2010).

[23] Vescio, Vicki, Dorene Ross, and Alyson Adams. "A review of research on the impact of professional learning communities on teaching and student learning." Teaching and teacher education 24, no.1 (2008): 80-91.

[24] von Glasersfeld, Ernst. "An interpretation of Piaget's constructivism." Revue internationale de philosophie (1982): 612-635.

[25] Vygotsky, Lev Semenovich. Mind in society: The development of higher psychological processes. Harvard university press, 1980.

[26] Whittaker, Chris, and Elizabeth S. Charles. "Designed spaces and Learning Communities as agents of change in pedagogical capacity: An example of moving beyond the researcher-practitioner divide." 